\title{
The Effects of Fuel Film on Soot Formation of GDI Injector using Optical Diagnostics
}

Jongwon Chung ${ }^{1}$, Woojae Kim ${ }^{1}$, Junghyun Kim¹, Kyoungdoug Min¹, Jonghwa Lee ${ }^{2}$

${ }^{1}$ Department of Mechanical Engineering, Seoul National University, 1 Gwankak-ro, Gwankak-gu, Seoul, Korea

${ }^{2}$ Department of Mechanical Engineering, Ajou University, 206 World cup-ro, Yeongtong-gu,

Suwon 16499, Gyeonggi, Korea

*Corresponding author email : kdmin@snu.ac.kr

\begin{abstract}
Particulate matter emission regulations have become increasingly stringent, impacting gasoline direct injection (GDI) engines. Therefore, it is necessary to understand the fuel film and soot emission characteristics. In this study, optical methods were used to understand the fuel film and soot formation characteristics.

Laser-induced fluorescence (LIF) is one of methods for fuel film measurement. In this study, the total internal reflection (TIR) LIF method was applied to eliminate the fluorescence signal of airborne droplets. For investigation of soot, diffused back illumination extinction imaging (DBIEl) method was used in this study. The extinction of light is due to sum of the scattered and absorbed intensity by the soot clouds. Constant volume combustion chamber (CVCC) was constructed to make engine-like condition.

The fuel film and soot emission characteristics was investigated. From the DBIEl images, soot formation process was investigated. After flame propagation is finished, soot formation was occurred on the entire bottom surface where fuel-rich region was formed. After that, fuel was evaporated from film constantly and results into soot pyrolysis. With injection duration variation, as injection duration increases, both fuel film and soot mass were increased. It is demonstrated that fuel film reduction is a key factor for soot formation reduction.
\end{abstract}

\section{Keywords}

GDI injector, Fuel film, Laser induced fluorescence (LIF), Soot, Diffused back illumination extinction imaging (DBIEI)

\section{Introduction}

Currently, gasoline direct injection (GDI) engines have replaced conventional port fuel injection (PFI) gasoline engines because of higher thermal efficiency. As the fuel is directly injected into the combustion chamber, fuel evaporation during intake and compression stroke enable intake charge cooling. This charge cooling affects knock tendency and results in the possibility of increasing the compression ratio. However, direct injection of fuel into the combustion chamber might result into fuel impingement on the top of the piston and cylinder wall [1]. In addition, air-fuel mixing time would be decreased and might cause the formation of a less homogeneous mixture. As a result, soot emission can be severely problematic in GDI engines as a result of mixture inhomogeneity, deposition on injectors, and fuel film deposition [2].

In GDI engine, the solid component of the particulate is largely soot. This soot forms when gasoline vapor evaporates from the liquid-fuel films and mixes with the hot burned gases [3]. This region is fuel-rich condition with hot enough for soot formation, and soot forms. As combustion and emission characteristics are mainly influenced by spray injection strategies, soot emission characteristics were investigated with varying operating conditions and injection strategies. 
Previous studies mainly focused on two aspects for the soot emission characteristics: mixture homogeneity and wall film formation. Previous researches demonstrated wall film formation is more severe in cold start condition. It has been demonstrated that soot formation is not caused by diffusion flame, and the flame-like luminosity comes from spray pyrolysis in fuel rich plumes originating from liquid fuel film on the cylinder walls [4]. Further investigation is needed for relation between wall film formation and soot pyrolysis.

The characteristics of fuel films have been studied by several researchers using numerous technologies. Schulz et al. [5] developed an IR thermography method to understand fuel films and the spray-wall interaction. Refractive index matching (RIM) is another film thickness measurement method and was developed by Drake et al. [6]. However, the measurement range of the RIM technique is limited by the surface roughness because the scattered light intensity does not change once the film thickness exceeds the surface roughness.

Laser-induced fluorescence (LIF) is a widely applied fuel film thickness measurement technique. LIF is spontaneously emitted from an atom or molecule that has been excited to a higher energy level by the absorption of laser light. The LIF signal is intensity is related to film thickness, which means suitable method for thickness measurement.

Although LIF is widely used for thickness measurement, it has several challenges in acquiring quantitative film results. When Laser beam emits from the bottom of the quartz and passes through both the fuel film and airborne droplets after fuel injection. These airborne droplets could be cause fluorescence error. The concept of the total internal reflection (TIR) method was introduced to eliminate this fluorescence disturbance [7].

For soot visualization, Laser induced incandescence (LII) is one of the representative techniques for measuring quantitative soot volume fraction with high accuracy. However, LII method needs calibration for quantification, and additional laser extinction method (LEM) is needed for measuring soot concentration. In addition, laser attenuation problem could be occurred if the measurement is progressed in the high soot cloud environment [8].

Diffused back illumination extinction imaging (DBIEI) is another method for soot measurement based on extinction imaging technique. The extinction of light is due to sum of the scattered and absorbed intensity by the soot clouds. Two-dimensional line of sight extinction imaging with high-speed LED operation enable high temporal resolution data analysis. However, studies using DBIEl are mostly focused on the diesel spray analysis.

There are lack of researches of pyrolysis and soot formation from the fuel film in GDI engines, and quantitative analysis of soot formation is not conducted yet. In this paper, soot emission characteristics by fuel film were investigated using optical diagnostics.

\section{Film Quantification Methodology}

In the LIF method, fluorescent tracer are specified by a molar concentration $C$ with a quantum yield $\varnothing$ and a molar absorption coefficient $\varepsilon$. The tracer is excited with an initial radiation $I_{0}$. The film thickness $h$ is determined by measuring the fluorescence signal of $I_{\text {f }}$. Using the BeerLambert law, the film thickness $h$ can be calculated by following equation.

$$
I_{f}=I_{0} \varnothing\left(1-10^{-\varepsilon C h}\right)
$$

The film thickness $h$ is on the order of $10^{-5} \mathrm{~m}$, and the index term of 10 in Equation (1) approximates zero. Therefore, Equation (1) can be transformed into

$$
I_{f}=I_{0} \varepsilon \emptyset C h
$$




\section{Soot Quantification Methodology}

As DBIEI method is an extinction-based diagnostic, the soot volume fraction is related to the light intensity that has been absorbed or scattered by the soot cloud. The two-dimensional extinction images could be converted to optical thickness, $\mathrm{KL}$, using the Beer-Lambert law:

$$
I=I_{0} \exp (-K L)
$$

Where $I$ is measured intensity of soot cloud, $I_{0}$ is incident intensity, and $K$ is the dimensional extinction coefficient and $L$ is the path length through the soot cloud. The soot volume fraction could be calculated by following equation derived from small particle Mie theory [9].

$$
f_{v}=K \lambda / k_{e}
$$

Where $f_{v}$ is the soot volume fraction, $\lambda$ is incident light wavelength and $k_{e}$ is the dimensionless extinction coefficient. $k_{e}$ could be calculated by following equation.

$$
k_{e}=\left(1+\alpha_{s a}\right) \cdot 6 \pi \cdot E(m)
$$

$\alpha_{s a}$ is the ratio of the scattering to absorption cross-sections and is imaginary part of $\left(m^{2}-1\right) /\left(m^{2}+2\right)$, where $\mathrm{m}$ is the complex refractive index of the soot particles. Combining equation (3) and (4), total soot mass could be calculated by

$$
m_{\text {eoot }}=\iint \rho_{\text {soot }} \cdot \lambda / k_{e} \cdot\left(-I / I_{0}\right) \cdot d A
$$

The density range could be varied from $1.0 \mathrm{~g} / \mathrm{cm}^{3}$ to $1.8 \mathrm{~g} / \mathrm{cm}^{3}$. In this study, soot density 1.8 $\mathrm{g} / \mathrm{cm}^{3}$ was applied based on several studies. The dimensionless extinction coefficient is dependent upon the soot refractive index and is related to particle morphology, such as primary particle size, the number of primary particles per aggregate, and the physical arrangement of particles. In this paper, $k_{e}$ value was selected suggested by Skeen et al. [10].

\section{Experimental Setup and Operating Condition}

Experiments were conducted in a cubical constant volume combustion chamber (CVCC) to make engine-like condition. Two side planes have an optical access with $100 \mathrm{~mm}$ diameter and bottom plane has an optical access for film imaging. The chamber inside is described in Figure \#. On the top of the chamber, a single-hole GDI injector and pressure sensor are mounted. The chamber was heated at $373 \mathrm{~K}$ using $3 \mathrm{~kW}$ electric heating system. To improve temperature distribution inside the chamber, fan is installed on the side plane and operated at $1,000 \mathrm{rpm}$. Spark plug is installed on the opposite side of fan. The chamber pressure was measured using pressure sensor.

The film measurement and soot measurement were progressed simultaneously. The experimental setup is shown in Figure \#. For film measurement, An Nd:YAG laser (Continuum PL 8000) was used for the LIF film experiment, and a $355 \mathrm{~nm}$ laser beam with third-harmonic generation was used for the gasoline fuel excitation. A novel designed quartz and quartz install module enable TIR-LIF condition without causing any sealing problem in CVCC. The LIF signals were detected by a high-speed ICCD camera.

For soot measurement, a 632-nm red LED (LED Engin LZ4) was used as a light source and aspheric lens was used as a collimator. A $150 \mathrm{~mm}$ f/1 Fresnel lens was placed away from the LED. And $100 \mathrm{~mm}$ diameter Luminit holographic diffuser was installed just in front of the optical window of the CVCC. Band-pass filter and ND filter were installed in front of the camera to reduce the natural flame luminosity. The DBIEI signals were detected by a high-speed CMOS camera. 
Experiments were conducted by following procedure. First, inlet gas filling process was progressed. This gas filling process take about three minutes, to make inlet gas heated up enough and electric fan is operated to make uniform distribution of inlet gas. After gas filling is finished, GDI injection is occurred. At this time, film images were captured at ASOI (after start of injection) $10 \mathrm{~ms}$ and $110 \mathrm{~ms}$. The ignition was occurred at ASOI $150 \mathrm{~ms}$. Flame is propagated from spark plug and soot is formed by pyrolysis after the hot burned gas reaches fuel film. DBIEl imaging was conducted during combustion and after combustion.

The operating conditions are listed in the Table 1. CVCC was operated at chamber pressure $0.3 \mathrm{MPa}, \lambda=1$ condition. The $\lambda=1$ condition is based on methane and air ratio, and did not consider gasoline fuel vaporization. The chamber initial temperature was set at $373 \mathrm{~K}$ and electric fan was operated to maintain homogeneous temperature distribution inside the chamber. A six-hole GDI injector was used, and five of its holes were sealed by laser welding to make it a single-hole injector. A commercial gasoline fuel was used in the experiments, and the fuel was pressurized by high pressure-compress nitrogen gas. The distance between injector tip and bottom plate was $50 \mathrm{~mm}$, while the impinging angle was $90^{\circ}$. Each case was repeated ten times.

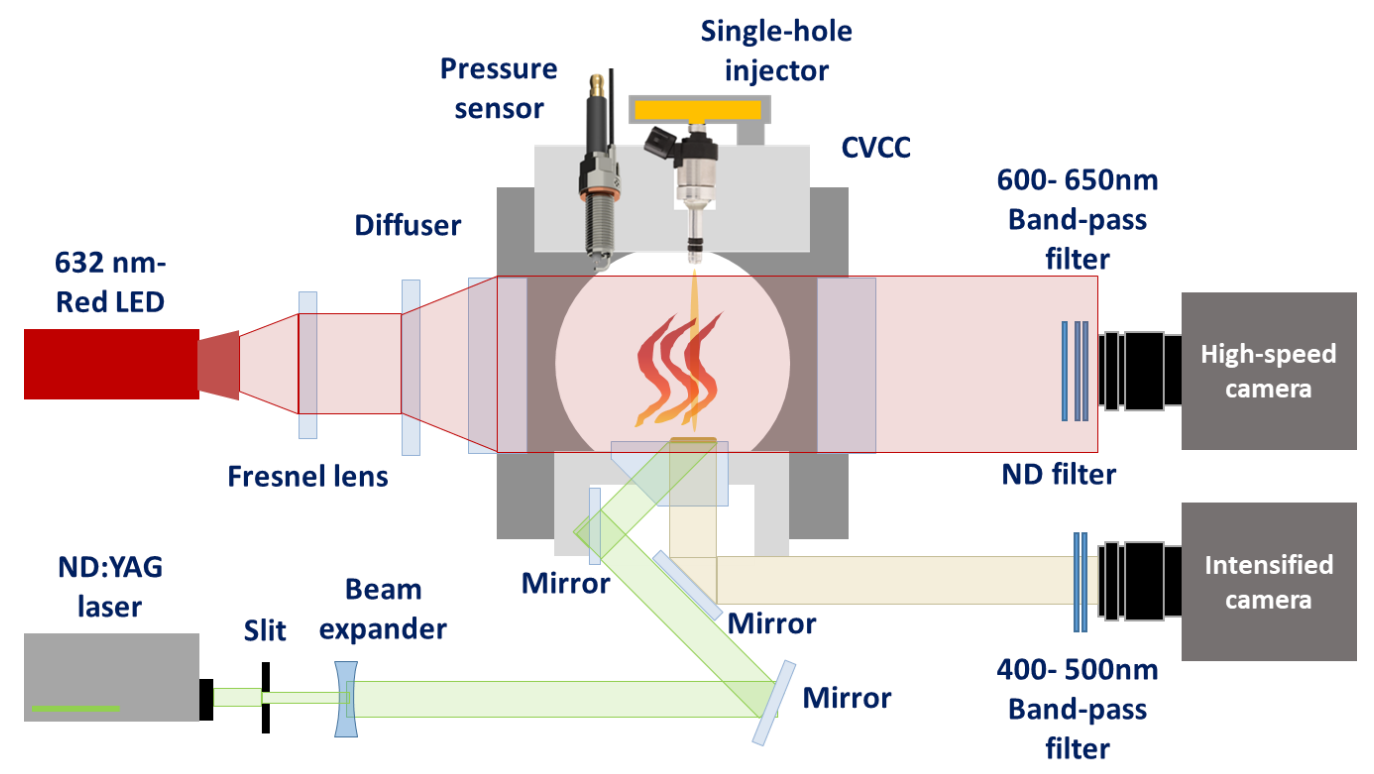

Figure 1. Experimental setup for fuel film and soot measurement

Table 1. Operating Conditions

\begin{tabular}{|c|c|}
\hline Description & Specification \\
\hline Initial chamber pressure [MPa] & 0.3 \\
\hline Initial chamber temperature $[\mathrm{K}]$ & 373 \\
\hline Injector tip temperature $[\mathrm{K}]$ & 373 \\
\hline Bottom quartz temperature [K] & 373 \\
\hline Air-fuel equivalence ratio $(\lambda)$ & 1.0 \\
\hline Ignition timing [ms] & $150 \mathrm{~ms}$ ASOI \\
\hline Injection duration [ms] & 5 \\
\hline Injection pressure [MPa] & 10 \\
\hline
\end{tabular}




\section{Fuel Film and Soot Emission Characteristics}

Fuel film and soot emission characteristics were investigated under ambient pressure $0.3 \mathrm{MPa}$, 5 ms gasoline fuel injection with injection pressure $10 \mathrm{MPa}$.

Figure 2 shows spray images using DBIEI method. The upper side images are $I / I_{0}$ images while bottom side images are raw images. With $1 / I_{0}$ images, air-borne droplets are well visualized compared to raw images. Measured fuel injection mass was $15.29 \mathrm{mg}$. Spray hit the bottom quartz plate and wall impingement was occurred at ASOI $1 \mathrm{~ms}$. Simultaneously, fuel droplets splashed toward the side position. The fuel injection was finished at ASOI $6.4 \mathrm{~ms}$ and at ASOI 10ms, air-borne droplets were almost disappeared.

Figure 3 shows LIF film images at ASOI $10 \mathrm{~ms}$ and ASOI $110 \mathrm{~ms}$ respectively and Table 2 shows film mass, area, and average thickness data. The capture timing at ASOI $10 \mathrm{~ms}$ was selected to measure film image at maximum film formation timing. At ASOI $10 \mathrm{~ms}$, the film mass was $3.81 \mathrm{mg}$, and about $24.9 \%$ of fuel mass was deposited on the quartz surface. As there are shot-to-shot variation of both fuel injection and laser intensity, the standard deviation of film mass was quite large while the film area has small standard deviation. As injection time elapsed, film area was increased while film mass was similar. As a results, average film thickness was decreased.
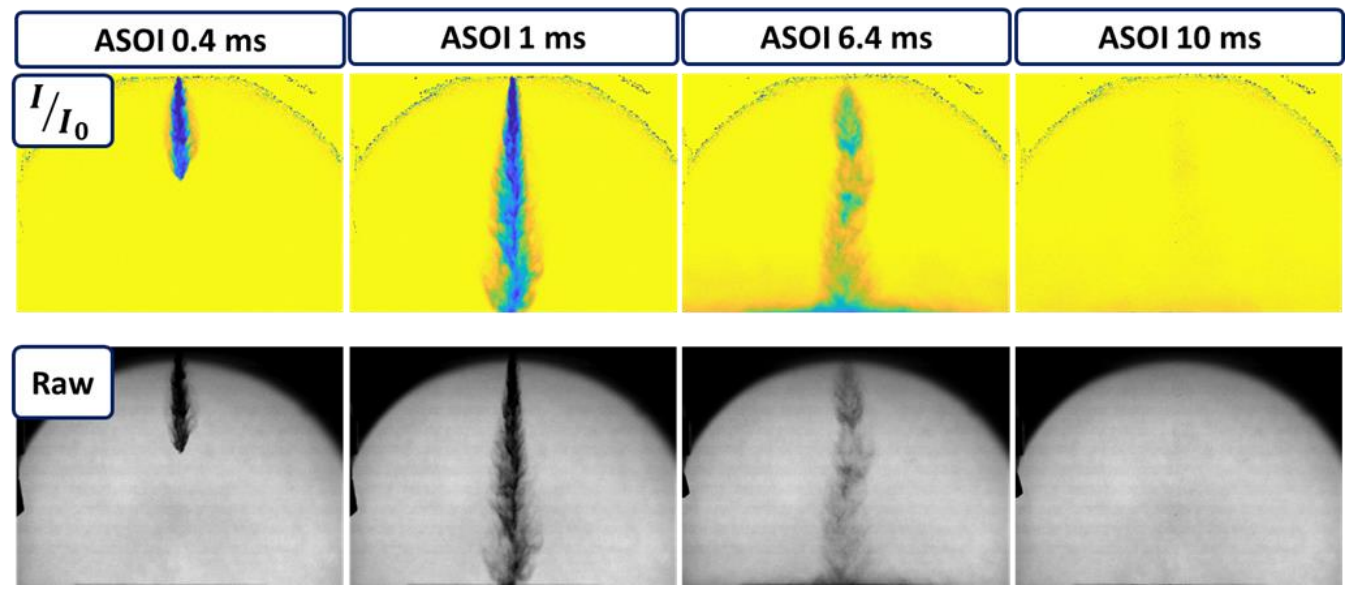

Figure 2. Spray images acquired by DBIEI method. The top figures are $\mathrm{I} / \mathrm{l}$ o profile while the bottom figure $\mathrm{s}$ are raw spray images.

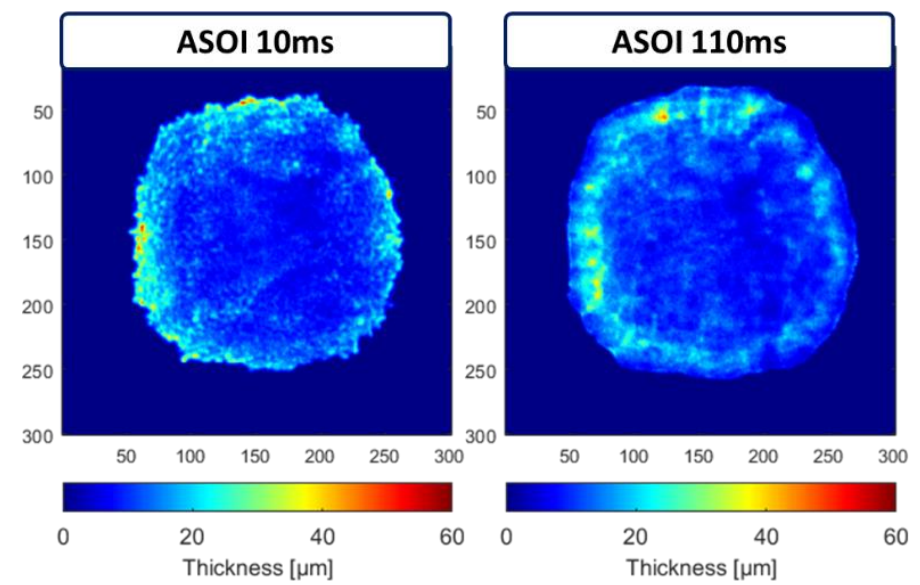

Figure 3. Fuel film images at ASOI $10 \mathrm{~ms}$ (left) and ASOI $110 \mathrm{~ms}$ (right). 
Table 2. Fuel film characteristics of 5 ms injection with injection pressure 100 bar and ambient pressure 3 bar

\begin{tabular}{|c|c|c|}
\hline Parameters & ASOI 10 ms & ASOI 110 ms \\
\hline Film mass [mg] & 3.81 & 3.80 \\
\hline Film area [mm²] & $\mathbf{4 3 1 . 3 1}$ & $\mathbf{4 8 4 . 7 5}$ \\
\hline Average film thickness [um] & $\mathbf{8 . 8 4}$ & $\mathbf{7 . 8 6}$ \\
\hline
\end{tabular}

The KL-factor images over the entire combustion process is shown in the Figure 4 . The results showed maximum KL-factor near 3, which means that attenuation with high $\mathrm{KL}$ was not observed in the present study. The images showed that soot formation is only occurred near the bottom surface. Flame front reached at film about $35 \mathrm{~ms}$ alGN. Rapid soot formation was observed at $50 \mathrm{~ms}$ alGN and this time difference of $15 \mathrm{~ms}$ is about 144 crank angle (CA) at 1600 RPM engine operation. These soot formation behavior could be observed in engine operation condition. During this period, soot height was about $10 \mathrm{~mm}$. Soot cloud height was reached up to about $30 \mathrm{~mm}$ at $70 \mathrm{~ms}$ alGN, which could be converted into $340 \mathrm{CA}$ at 1600 RPM which is near the end of exhaust stroke. Considering that there was no flow inside the chamber before ignition, soot cloud height could be higher at engine operation condition.
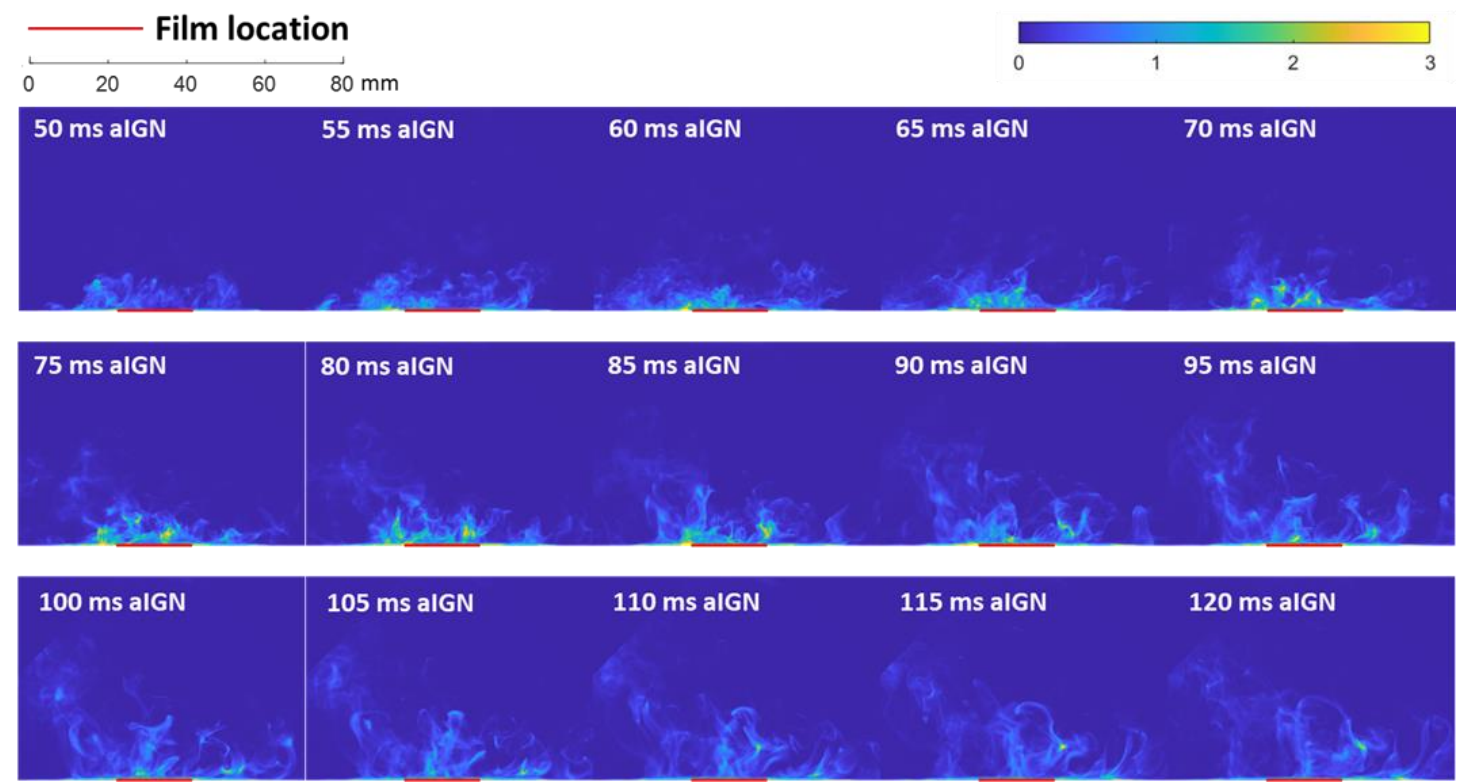

Figure 4. KL factor images during pyrolysis of fuel film

To understand the soot formation process, several KL-factor images were matched with calculated soot mass results in Figure 5. Flame propagation was almost finished at $40 \mathrm{~ms}$ alGN. At this timing, soot formation was not observed as temperature was not high enough. At $50 \mathrm{~ms}$ alGN, soot formation was visualized and soot was formed near the entire quartz plate. This soot formation behavior was lasted until $60 \mathrm{~ms}$ alGN. In this primary period, the soot formation rate is faster than any other period during combustion. Additional soot formation is occurred slowly after fast soot formation is finished. Soot formation is significantly reduced about $160 \mathrm{~ms}$ alGN. In this stage, universal temperature is below $1,300 \mathrm{~K}$, and soot formation is significantly decreased for hydrocarbon fuels [65]. Although the film still exists in this period, the film evaporate on in this period is less effective at soot generation.

Based on the results, the soot formation by fuel film could be categorized into three stages. On the $1^{\text {st }}$ stage, approximately between $45 \mathrm{~ms}$ to $60 \mathrm{~ms}$, spray pyrolysis is occurred at entire bottom surface, where is estimated as a fuel rich region originated from fuel film. After fuel 
injection, spray hits the bottom surface and splash towards the side position of the bottom surface. As there is no additional source of flow motion, fuel droplets are remained on the bottom surface after spray-wall interaction. In addition, fuel evaporation is occurred on the film slowly and fuel-rich region is formed. Therefore, soot is formed on the entire bottom surface. After rapid soot formation is finished, soot mass increased slowly. This is the $2^{\text {nd }}$ stage of soot formation. In this period, the soot formation region is limited to near the film area. The fuel rich combustion of air-fuel mixture by spray-wall interaction is finished. However, from the fuel film, the fuel keep evaporated and additional source of spray pyrolysis is only comes from fuel film. The final stage showed that there is no soot formation as temperature is decreased and pyrolysis is not occurred. In this stage, fuel film is still existed but do not affects soot formation.

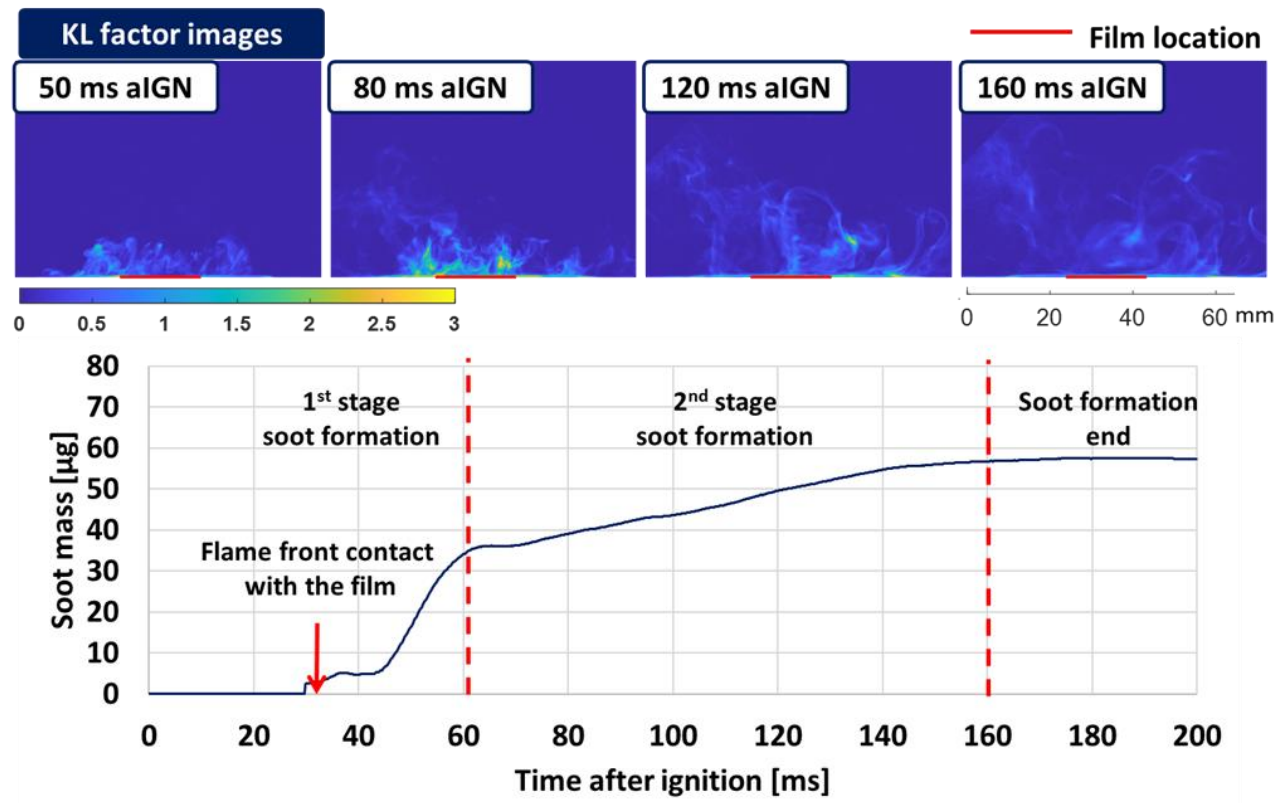

Figure 5. Soot formation stages

\section{Conclusions}

In this study, fuel film and soot emission characteristics were investigated using optical methods under GDI condition. CVCC was constructed to make engine-like condition. Fuel film was measured using TIR-LIF method and soot was measured using DBIEI method. To apply TIR-LIF under high pressure condition, a special quartz design was applied and simultaneous imaging of film and soot could be achieved. Soot formation was measured using DBIEI method. DBIEl imaging was conducted during combustion process.

The fuel film and soot emission characteristics were investigated at injection pressure $10 \mathrm{MPa}$, $5 \mathrm{~ms}$ duration at ambient pressure 3 bar. The fuel film mass was about $3.81 \mathrm{mg}$ and the average thickness was about $8.84 \mu \mathrm{m}$. From the DBIEl images, soot formation process was investigated. At $35 \mathrm{~ms}$ after ignition, flame front reached film surface but soot formation was not observed. Soot formation was observed on the entire bottom surface at $40 \mathrm{~ms}$ alGN. From the soot mass results, soot formation could be divided into three stages. At $1^{\text {st }}$ stage, soot was formed on the entire bottom surface, not only the area where film is formed. In this stage, the air-fuel equivalence ratio $(\lambda)$ was low on the bottom plate and soot formation rate was fast. At $2^{\text {nd }}$ stage, soot was formed from where film locates as fuel is vaporized from fuel film slowly. As soot formation was occurred only by fuel evaporation from film, the formation rate was decreased compared to 1st stage. At last stage, soot formation was finished and soot clouds move randomly in the chamber. This research includes fuel film and soot measurement under GDI engine condition using optical methods. The experimental data presented in this study 
could be used for CFD modeling. With combination of another optical diagnostics, the entire soot formation process could be explained.

\begin{tabular}{ll}
\multicolumn{2}{l}{ Nomenclature } \\
aIGN & after ignition \\
aSOI & after start of injection \\
CVCC & Constant volume combustion chamber \\
DBIEI & Diffused back illumination extinction imaging \\
GDI & Gasoline direct injection \\
LEM & Laser extinction method \\
LIF & Laser induced fluorescence \\
LII & Laser induced incandescence \\
RIM & Refractive-index matching \\
TIR & Total internal reflection
\end{tabular}

\section{References}

[1] Fu, H., Wang, Y., Li, X., and Shuai, S.-J., 2014, "Impacts of cold-start and gasoline RON on particulate emission from vehicles powered by GDI and PFI engines," No. 0148-7191, SAE Technical Paper.

[2] Steimle, F., Kulzer, A., Richter, H., Schwarzenthal, D., and Romberg, C., 2013, "Systematic analysis and particle emission reduction of homogeneous direct injection SI engines," SAE Technical Paper Series.

[3] Heywood, J. B., 2018, Internal Combustion Engine Fundamentals, McGraw-Hill Education. [4] Ketterer, J. E., and Cheng, W. K., 2014, "On the nature of particulate emissions from DISI engines at cold-fast-idle," SAE International Journal of Engines, 7(2), pp. 986-994.

[5] Schulz, F., Schmidt, J., Kufferath, A., and Samenfink, W., 2014, "Gasoline Wall Films and Spray/Wall Interaction Analyzed by Infrared Thermography," SAE International Journal of Engines, 7(3), pp. 1165-1177.

[6] Drake, M. C., Fansler, T. D., Solomon, A. S., and Szekely Jr, G., 2003, "Piston fuel films as a source of smoke and hydrocarbon emissions from a wall-controlled spark-ignited directinjection engine," SAE Technical Paper Series, pp. 762-783.

[7] Kull, E., Wiltafsky, G., Stolz, W., Min, K., and Holder, E., 1997, "Two-dimensional visualization of liquid layers on transparent walls," Optics letters, 22(9), pp. 645-647.

[8] Sjöholm, J., Wellander, R., Bladh, H., Richter, M., Bengtsson, P.-E., Alden, M., Aronsson, U., Chartier, C., Andersson, O., and Johansson, B., 2011, "Challenges for In-Cylinder HighSpeed Two-Dimensional Laser-Induced Incandescence Measurements of Soot," SAE International Journal of Engines, 4(1), pp. 1607-1622.

[9] Pickett, L. M., and Siebers, D. L., 2004, "Soot in diesel fuel jets: effects of ambient temperature, ambient density, and injection pressure," Combustion and Flame, 138(1-2), pp. 114-135.

[10] Skeen, S., Yasutomi, K., Cenker, E., Adamson, B., Hansen, N., and Pickett, L., 2018, "Standardized Optical Constants for Soot Quantification in High-Pressure Sprays," SAE International Journal of Engines, 11(6), pp. 805-816. 


\section{Response to reviewer comments}

\section{Reviewer \#1:}

Comments :

I do not follow how you went from equation (1) to (2). Unless there is an error in the paper, the only way to create equation (2) from equation (1) is to assign a molar coefficient of $\sim 0.43$. In the Experimental Setup and Operating Conditions section you mention that the air-fuel ratio is set to stoichiometric based on methane only and ignoring any gasoline vaporization. Am I to conclude that the chamber is being filled with a methane-air mixture and you're injecting gasoline into it? There is no other mention of methane anywhere else in the paper. Assuming you are injecting into a stoichiometric environment, perhaps you should comment on the formation and evolution of soot in the chamber during combustion of an overall-rich system vs. a normal GDI injection. As an outside observer, it seems to me having no oxygen left after the flame has passed would have a very large impact on the lifespan of soot formed during pyrolysis.

\section{How went from equation (1) to (2)}

$\rightarrow$ There was an error on equation (2). I revised the equation : $I_{f}=I_{0} \varepsilon \emptyset C h$

2. Whether chamber is being filled with a methane-air mixture and injecting gasoline into it

$\rightarrow$ Yes, the chamber was filled with a methane-air mixture and ignited before injecting gasoline. Gasoline was injected after ignition was occurred.

\section{Difference between overall-rich system vs. a normal GDI injection}

$\rightarrow$ Whether overall-lambda is stoichiometric or rich, fuel film is formed after gasoline injection and fuel-rich region is formed near the film plate. Soot is formed on this fuel-rich region. Soot formation condition between overall-rich system and normal GDI condition could not be identical, but there might be little difference. I also conducted overall-lean condition but soot formation was occurred by gasoline injection. 